Research paper

\title{
Hygienic coatings with bioactive nano-additives from Senna occidentalis- mediated green synthesis
}

\author{
Leyanet Barberia-Roque ${ }^{\mathrm{a}}$, Olayide Folashade Obidi ${ }^{\mathrm{b}}$, Erasmo Gámez-Espinosa ${ }^{\mathrm{a}}$, Marisa Viera ${ }^{\mathrm{a}, \mathrm{c}}$, \\ Natalia Bellotti ${ }^{\mathrm{a}, \mathrm{C}, *}$ \\ ${ }^{a}$ CIDEPINT-Centro de Investigación y Desarrollo en Tecnología de Pinturas (CICPBA-CONICET-UNLP), Calle 52 e/ 121 y 122, B1900AYB La Plata, Argentina \\ ${ }^{\mathrm{b}}$ Department of Microbiology, University of Lagos, Nigeria \\ ${ }^{c}$ CONICET-UNLP, Argentina
}

\section{A R T I C L E I N F O}

Editor: Chunying Chen

Keywords:

Hygienic coatings

Nanoparticles

Senna occidentalis

Biocide

Biodeterioration

Paints

\begin{abstract}
A B S T R A C T
Nowadays urban populations spend $90 \%$ of their time in buildings where microbial growth lead to hazardous environments which produce health problems characterized by irritation of the respiratory tract, infections, allergies and asthma. Some research lines seek to obtain antimicrobial materials to prevent such health problems. Green synthesis of different nanoparticles was carried out to explore their antimicrobial potential. Solutions of silver, copper, cerium, lanthanum and zinc salts were used as source of metal ions for the synthesis process. Aqueous plant extract from Senna occidentalis, a small shrub, was used, for the first time, as reducing and stabilizing agent to obtain additives to bioactive coatings. The stable synthesis products were evaluated by UV-vis spectroscopy and their antimicrobial properties were assessed. Other characterizations by transmission electron microscopy and Fourier transformed infrared spectroscopy were also performed. Silver and copper nanoparticles were stable over time. However, only silver nanoparticles showed antibacterial and antifungal activity and were used for obtaining antimicrobial waterborne acrylic paints. The formulation with $25 \mathrm{mg} / 100 \mathrm{~g}$ resulted in efficient inhibition of the fungal and bacterial biofilm.
\end{abstract}

\section{Introduction}

Poor indoor environmental quality is associated with a range of health problems from transient sensory irritation of the respiratory tract to diseases that can be life threatening (Dubey, 2016). Among the microbial indoor air pollutants, bacteria and fungi are highly relevant ( $\mathrm{Li}$ and Yang, 2004; Weber et al., 2013). An example of this is the increased levels of endotoxins from Gram-negative bacteria in indoor dust which was associated with increases in asthma symptoms (Jansz, 2016). Indoor mold growth due to the presence of water available by leakages, condensation and increase in relative humidity by natural human activity in kitchen and bathroom also constitutes an important source of pollution (Adan and Samson, 2011; WHO, 2009). Two decades ago the World Health Organization published a bulletin explaining the chemical nature of various mycotoxins and the etiology of disease due to production of specific mycotoxin by mold species (Peraica et al., 1999). Epidemiologic studies have associated mold sensitivity, particularly to Alternaria alternata and Cladosporium herbarum, with the development, persistence, and severity of asthma which is the most common chronic respiratory disease in all countries (Knutsen et al., 2012; Li and Yang, 2004). One of the strategies for avoiding cited health issues is the prevention of persistent dampness and microbial growth on indoor surfaces and in building structures (Jansz, 2016). In this sense, antimicrobial or hygienic coatings have a wide spectrum of functionality since they are designed to prevent both bacterial and fungal growth especially in medical and institutional sectors, food industry and dwelling (Falkiewicz-Dulik et al., 2015; Johns, 2003). The development of new eco-friendly component to functional coating formulation is intense at the present. This approach seeks to replace some questioned biocides due to their toxicity with similar or superior efficient ones such nanoparticles, quaternary ammonium salts, natural product and derivatives (Barberia-Roque et al., 2019; Clegg et al., 2019; Hendessi et al., 2016). In the last two decades nanoscale materials are intensively studied, their high surface/volume ratio produce an important effect on the properties of dispersed systems like paints (Haupert and Wetzel, 2005; Morones et al., 2005).

The bioactive properties of different nanoparticles have been studied especially of Ag, Cu, Se and Au (Adan and Samson, 2011; Mittal

\footnotetext{
* Corresponding author at: CIDEPINT-Centro de Investigación y Desarrollo en Tecnología de Pinturas (CICPBA-CONICET-UNLP), Calle 52 e/ 121 y 122, B1900AYB La Plata, Argentina.

E-mail address: n.bellotti@cidepint.ing.unlp.edu.ar (N. Bellotti).
} 
et al., 2013). Smaller particles increase the probability of contact with microorganisms and increase biocidal efficiency with lower concentrations. Use of aqueous plant extracts in the synthesis of nanoparticles (NPs) provides an efficient and low cost antimicrobial option (Barberia-Roque et al., 2019; Kumar et al., 2014). It is also environmentally friendly and suitable for large scale synthesis (Kumar and Yadav, 2009). The biogenic synthesis proposed by the present paper involves the synthesis of metal nanoparticles in aqueous medium containing phytochemical as reducing and stabilizing agents (Rajeshkumar and Bharath, 2017; Singh et al., 2016). The synthesis produces aqueous colloidal dispersions of NPs which could be used as additives to the formulation of hygienic waterborne coatings. The plant used is known to influence the nanoparticles properties due to the variation in the extract composition (Barberia-Roque et al., 2019; Mittal et al., 2013).

Although, the mechanism involved in the NPs antimicrobial activity, is not yet completely clarified, several published research point out that they interact with microbial membranes, inhibit the cell replication, alter nucleic acids and proteins, generate reactive oxygen spices (ROS) and release toxic ions (Chung and Toh, 2014; Lok et al., 2006; Nguyen Tri et al., 2019). Silver nanoparticles (NPs) and hybrid derivatives have been the most studied ones (Mittal et al., 2013; Nguyen-Tri et al., 2019). Therefore, the approach to other options such as cerium and lanthanum are promising for their huge potentialities (Roselli et al., 2014).

The present work proposes the synthesis of NPs from different metallic salts by a green method using Senna occidentalis L. aqueous extract for first time as reducing and stabilizing agents to be applied in the formulation of functional nano-based hygienic coatings. S. occidentalis belonging to Leguminoseae family was selected for its history of antimutagenic, antimicrobial and economic properties as well as its rich complements of phytochemicals (Odeja et al., 2015). In this work, the stable suspensions of NPs obtained were first characterized by UV-vis spectroscopy and their antimicrobial activity assessed by agar diffusion method on Escherichia coli (ATCC 11229), Staphylococcus aureus (ATCC 6538), Chaetomium globosum (KU936228) and Alternaria alternata (KU936229). Characterizations were done using transmission electron microscopy (TEM), Fourier transformed infrared spectroscopy (FTIR), scanning electron microscopy (SEM) and energy dispersive spectrometer (EDS). The selected nanoparticles were added in a waterborne paint formulation and the corresponding bio-resistance tests were carried out against the strains mentioned above to assess their antibacterial and antifungal properties (Barberia-Roque et al., 2019; Bellotti et al., 2013).

\section{Materials and methods}

\subsection{Plant extract: preparation and characterization}

Senna occidentalis leaves obtained from Lagos, Nigeria were identified and authenticated by Dr. A. Kadiri of the Department of Botany, University of Lagos, Nigeria. They were dried, milled in a kitchen blender and the aqueous extracts obtained by liquid-solid extraction method. $10 \mathrm{~g}$ of the sample was introduced into Milli-Q water $(100 \mathrm{~mL})$ at $80^{\circ} \mathrm{C}$. The extract was filtered and kept at $4{ }^{\circ} \mathrm{C}$ in caramel flasks (Deyá and Bellotti, 2017). The extract was screened for the presence of tannins, saponins, phlobatannins, flavonoids, alkaloids, terpenoids and glycosides (Odunayo et al., 2014). Gas chromatography-mass spectrometry (GC-MS) analysis of the sample was made diluting with n-hexane in a GC 7890 series coupled with MS detector (model 5975). Identification of compounds was achieved by comparing the retention times with those of authentic compounds and the spectral data obtained from the NIST Library.

\subsection{Nanoparticle synthesis}

The synthesis was done by mixing $10 \mathrm{~mL}$ of the extract with $90 \mathrm{~mL}$ of each salt solution at $60^{\circ} \mathrm{C}$ under constant stirring. The salts used were: $\mathrm{AgNO}_{3}, \mathrm{Cu}\left(\mathrm{NO}_{3}\right)_{2}, \mathrm{Ce}\left(\mathrm{NO}_{3}\right)_{3}, \mathrm{La}\left(\mathrm{NO}_{3}\right)_{3}$ and $\mathrm{Zn}\left(\mathrm{NO}_{3}\right)_{2}$ and the final concentrations in each synthesis system was $10^{-2} \mathrm{M}$. Milli-Q water was used for the synthesis and the $\mathrm{pH}$ was regulated to 7 with $\mathrm{NH}_{4} \mathrm{OH}$ $50 \% \mathrm{v} / \mathrm{v}$. Subsequently, the process was repeated with a lower salt concentration $\left(10^{-3} \mathrm{M}\right)$ in cases of those that were unstable at $24 \mathrm{~h}$. The synthesis products were kept at $4^{\circ} \mathrm{C}$ in caramel flasks. The conditions were selected based on previous results (Deyá and Bellotti, 2017).

\subsection{Characterization of the nanoparticles}

\subsubsection{UV-vis spectroscopy}

UV-vis spectra of the suspensions obtained were carried out in a Spectrum spectrophotometer (SP 2000 UV). Only stable suspensions were evaluated. The reduction of the metallic ions and the formation of nano-size particles produce specific bands of absorption in the UV-vis spectrum due to the surface plasmon resonance (Dipankar and Murugan, 2012; Shrivastava et al., 2007). Spectra were obtained from 200 to $650 \mathrm{~nm} 24 \mathrm{~h}$ and 30 days after synthesis.

\subsubsection{Antimicrobial activity}

Antimicrobial activity of stable suspensions was assessed using the agar diffusion method (Fernández and Bellotti, 2017). Firstly, antibacterial activity assay was performed and suspensions that proved active were then assessed for antifungal activity. Paper disks $(6 \mathrm{~mm}$ diameter) were impregnated with $6 \mu \mathrm{L}$ of each stable suspensions obtained. The antimicrobial activity of pure plant extract and metallic nitrate solutions were also evaluated. The culture media used for the assays were Mueller-Hinton (MH) agar and Malt Extract (ME) agar for bacterial and fungal strains, respectively. In the case of bacterial strains, overnight cultures of E. coli (ATCC 11229) and S. aureus (ATCC 6538) in $\mathrm{MH}$ broth were adjusted using phosphate buffer saline (PBS) to OD of 0.1 at $620 \mathrm{~nm}$ corresponding to $10^{8} \mathrm{CFU} / \mathrm{mL}$. The plates were subsequently seeded with the test organisms and corresponding disks placed on them and incubated at $37^{\circ} \mathrm{C}$ for $24 \mathrm{~h}$.

For the antifungal activity, the spore suspensions were prepared from C. globosum (KU936228) and A. alternata (KU936229) cultures. The inoculum concentration was adjusted by a Neubauer chamber to $10^{5}$ spores/mL. Plates with MEA inoculated with $200 \mu \mathrm{L}$ of spore suspensions were prepared. Embedded disks with nanoparticle suspensions were arranged on the plates. Finally, plates were incubated for $48 \mathrm{~h}$ at $28^{\circ} \mathrm{C}$.

At the end of incubation, plates were examined for inhibition zones, which were measured considering diameters $<6 \mathrm{~mm}$ to be without antibacterial and antifungal activity and $>6 \mathrm{~mm}$ to have antibacterial and antifungal activity. Diameters equal to 6 were considered to be indicative of antifungal activity but not antibacterial activity.

\subsubsection{Electron microscopy and infrared spectroscopy}

The size and shape of the NPs were assessed by TEM (JEOL 100CXII) and the analyses of micrographs were done to obtain average sizes of the NPs by Gatan Digital Micrograph software.

SEM micrographs were obtained by a Philips FEI Quanta $200 \mathrm{mi}-$ croscope and energy dispersive spectrometer for chemical analysis using X-rays (EDS) was also carried out.

FTIR spectra of the purified NPs and the dehydrated plant extract were obtained with a Perkin-Elmer Spectrum One Spectrometer using the $\mathrm{KBr}$ disk method. The NPs were purified by repeated centrifugation at $15,000 \mathrm{rpm}$ for $20 \mathrm{~min}$ at $20^{\circ} \mathrm{C}$ followed by re-dispersion of the pellet in Milli-Q water which was repeated three times (Deyá and Bellotti, 2017).

\subsection{Nano-based hygienic coating preparation}

Taking into account the results of the characterization, the more stable and bioactive suspension was selected for addition in an acrylic 

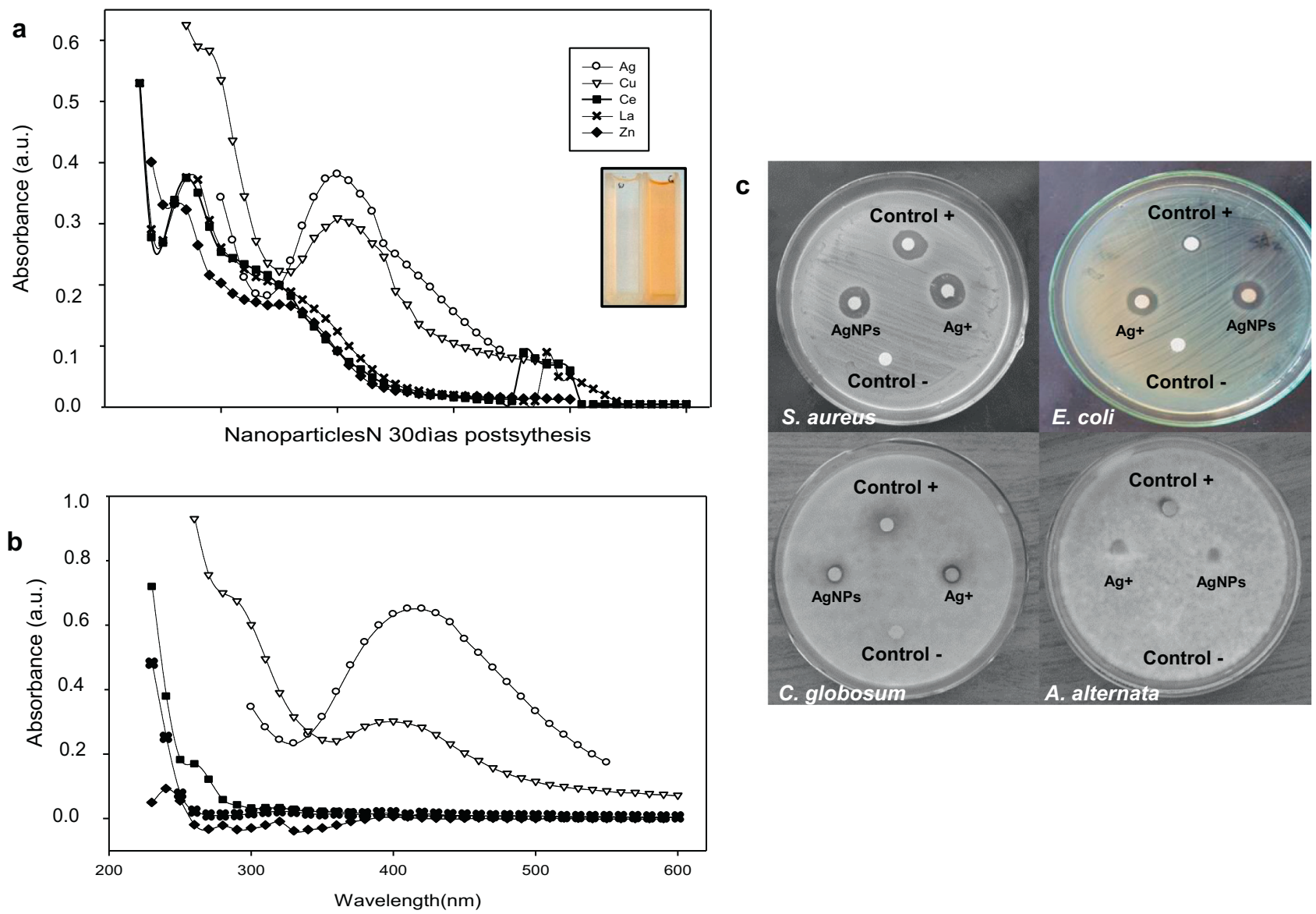

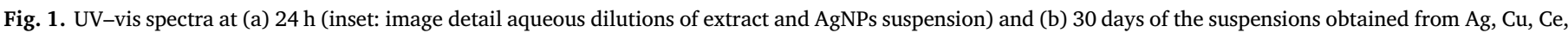

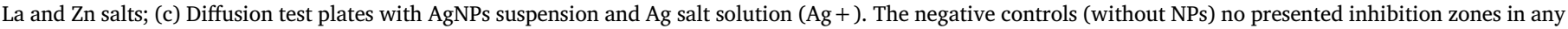
case.

waterborne paint formulation. In this sense, suspension from synthesis by plant extract and $\mathrm{AgNO}_{3}$ salt was the selected one. The paints were prepared with the following composition: $6.3 \%$ acrylic resin (1:1), $13.6 \% \mathrm{TiO}_{2}, 25.9 \% \mathrm{CaCO}_{3}$ (natural), $2.0 \% \mathrm{CaCO}_{3}$ (precipitated), $3.6 \%$ additives (antifoaming, cellulosic thickener, dispersants and surfactants) and $48.6 \%$ (\% by mass) of distilled water (DW). Different concentrations of the selected suspension with AgNps were used replacing the water formulation. The concentrations obtained and tested were: 10,15 and $25 \mathrm{mg}$ of silver per $100 \mathrm{~g}$ of paint, labelled as P10, P15 and $\mathrm{P} 25$, respectively. To the select the corresponding concentrations bibliography data were taken into account (Bellotti et al., 2015; Dominguez-Wong et al., 2014). Control coating (P) without any biocide was also evaluated.

\subsubsection{Fungal resistance assay}

Three of the glass slides of $6 \mathrm{~cm}^{2}$ were placed in plates with Minimum Mineral culture medium $\left(5 \mathrm{~g} \mathrm{NaCl}, 1 \mathrm{~g} \mathrm{HK} \mathrm{HO}_{4}, 1 \mathrm{~g}\left(\mathrm{NH}_{4}\right)\right.$ $\mathrm{H}_{2} \mathrm{PO}_{4}, 1 \mathrm{~g}\left(\mathrm{NH}_{4}\right)_{2} \mathrm{SO}_{4}, 0.2 \mathrm{~g} \mathrm{MgSO}_{4}, 3 \mathrm{~g} \mathrm{KNO}_{3}$ and $20 \mathrm{~g}$ of agar in $1000 \mathrm{~mL}$ of DW) with the coating up (Bellotti et al., 2015, 2013). The coating samples were inoculated with $50 \mu \mathrm{L}$ of the spore suspension $\left(10^{5}\right.$ spores $\left./ \mathrm{mL}\right)$ of $C$. globosum and A. alternata and incubated at $28{ }^{\circ} \mathrm{C}$ for 1 month (Bellotti et al., 2013).

Fungal growth was evaluated according to ASTM D5590 standard specification using naked eye and stereoscopic microscope. Consequently, observed growth on specimens are referred to percentage (\%) of area covered and has been rating as 0 (none, $0 \%$ ), 1 (trace of growth, < 10\%), 2 (light growth, 10-30\%), 3 (moderate growth, $30-60 \%$ ), and 4 (heavy growth, 60-100\%). Subsequently, these were observed by the scanning electron microscope (SEM) Philips FEI Quanta
200 at low vacuum (10-2-1 Torr). At the same time, a chemical analysis was carried out using an X-ray energy dispersion spectrometer (EDS) which is attached to the microscope.

\subsubsection{Antibacterial biofilm assay}

Microscope slide were painted with each paint sample and left to cure for two weeks. After that, they were decontaminated for $30 \mathrm{~min}$ on each side by irradiation with a germicide UV-lamp (Philips, $20 \mathrm{~W}$ ). The two bacterial strains, previously used in this work were sub cultured on Muller-Hinton broth of Britania brand at $30^{\circ} \mathrm{C}$ on rotary shaker at $125 \mathrm{rpm}$ by $18 \mathrm{~h}$. From these fresh pure cultures, bacterial suspensions $\left(10^{6} \mathrm{CFU} / \mathrm{mL}\right)$ were obtained. Painted slide pieces of $3,5 \mathrm{~cm} \times 2.5 \mathrm{~cm}$ were vertically introduced in sterile corning tubes, completely covered with $50 \mathrm{~mL}$ MHB and incubated during 5 days at $30^{\circ} \mathrm{C}$ (Barberia-Roque et al., 2018).The culture medium was replaced every day after first $48 \mathrm{~h}$.

Then samples were withdrawn and washed, three times, with phosphate buffer solution (PBS) to detach non-adhered cells. Later samples were fixed with a glutaraldehyde solution at $2 \% \mathrm{v} / \mathrm{v}$ in PBS and dried in an ethanol gradient. Finally, sputtering with gold was performed and the samples were observed in the same microscope mentioned above, this time at high vacuum mode (SEM).

\section{Results and discussion}

\subsection{Plant extract characterization}

The qualitative phytochemical screening of aqueous leaf extract of $S$. occidentalis showed the presence of tannins, saponins, flavonoids, 

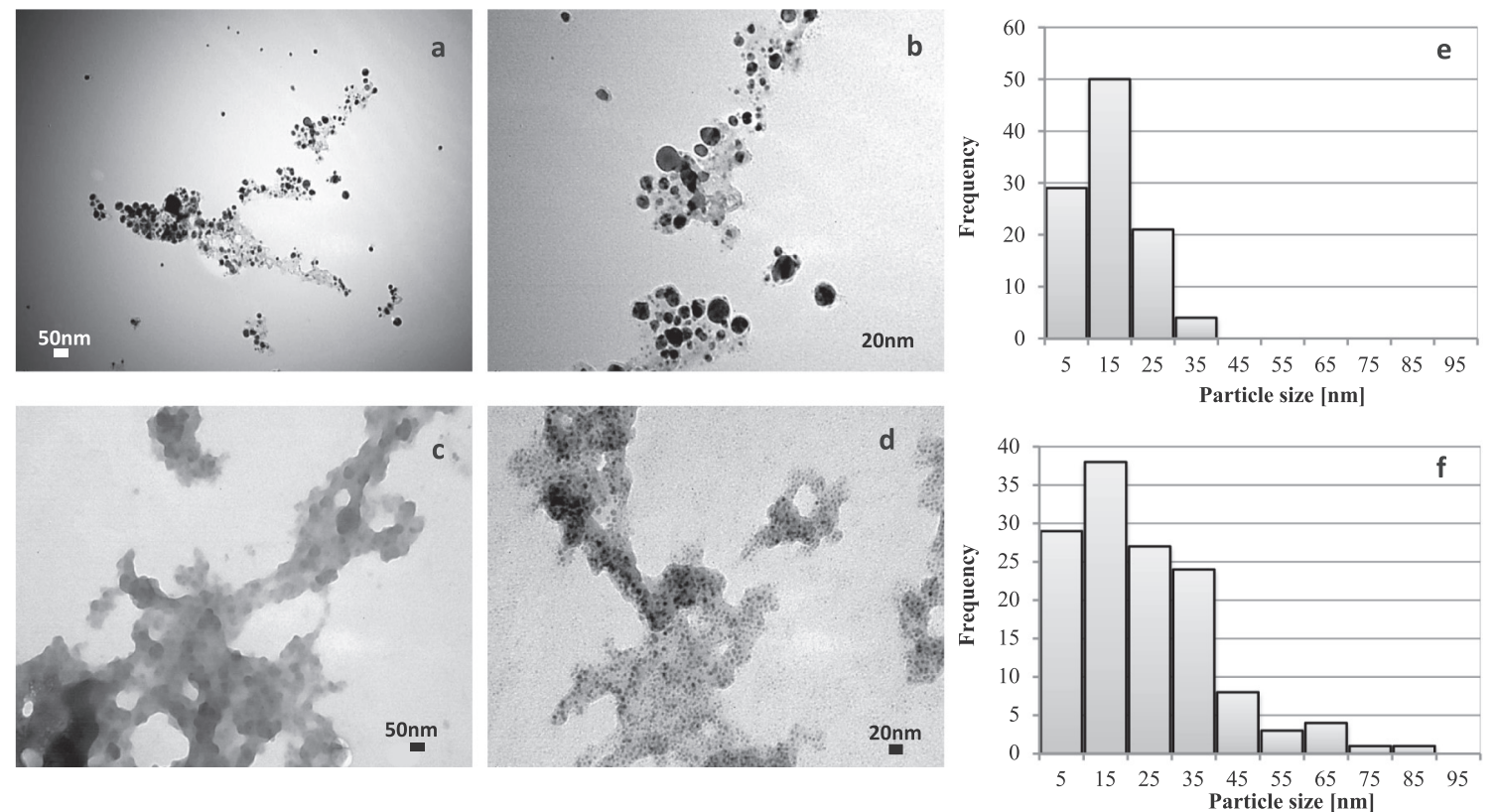

Fig. 2. TEM micrographs and histograms from size distribution analysis of AgNPs (a, b and e) and CuNPs (c, d and f). Magnification $100,000 \times(a, c)$ and $270,000 \times$ (b, d).

a

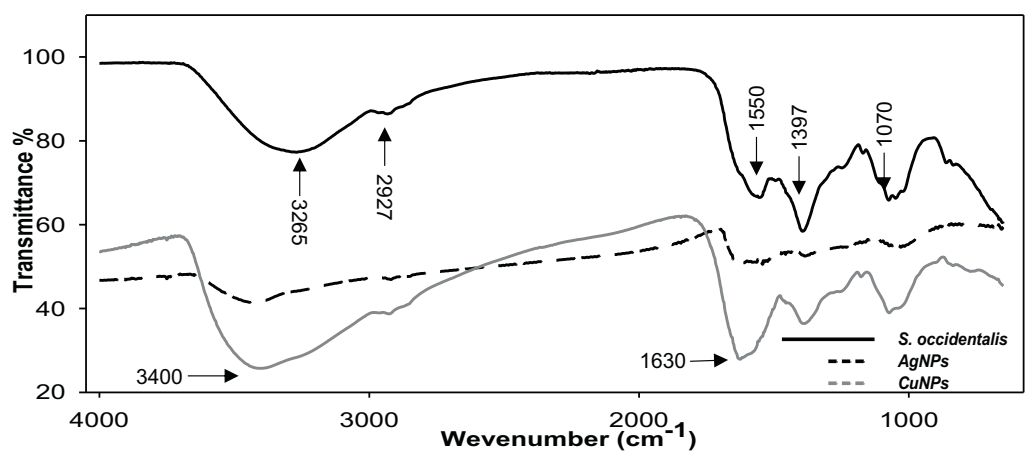

b

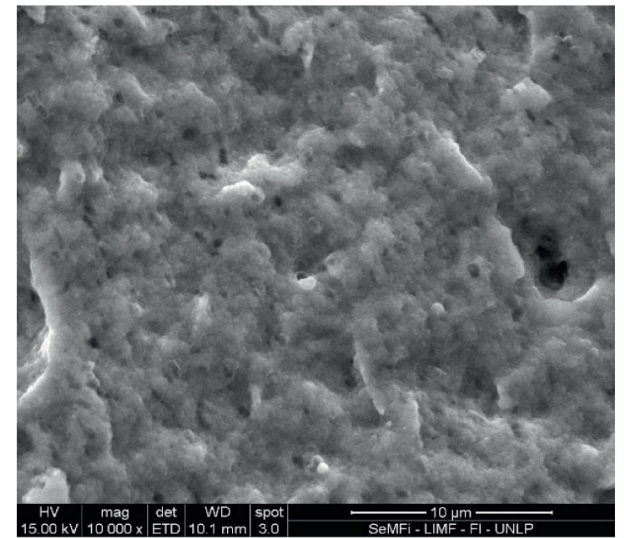

C counts

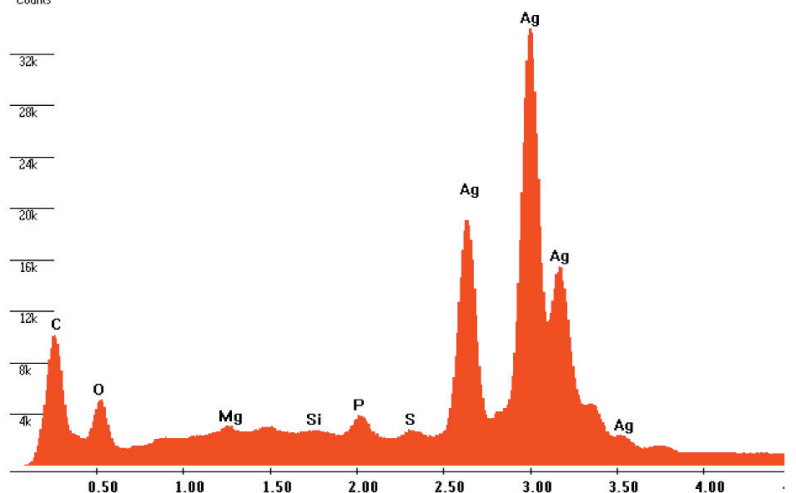

Fig. 3. FTIR spectra of Senna occidentalis extract, AgNPs and CuNPs purified from respective suspensions (a); SEM micrographs and EDS spectra of the same AgNPs (b, c).

alkaloids and terpenoids. The relative abundance of the compounds in the $S$. occidentalis extract determined by GC-MS was obtained from the analysis of the peak areas in correlation with the retention time. Identification of compounds was achieved by comparing the retention times with those of pure compounds and the spectral data obtained from the NIST Library. The most abundant compounds identified and the corresponding \% were: Pentadecanoic acid, 14-methyl, methyl ester (28.4\%); 9-octadecenoic acid (Z)-, methyl ester (25.8\%); 1,4-hexadiene, 2,3,4,5-tetramethyl- (15.9\%); 1,4-hexadiene, 2,3,4,5-tetramethyl(9.5\%); methyl stearate (7.9\%); 4-fluorobenzoic acid, 5-pentadecyl ester (7.7\%) and 2-trifluomethyl-5-hydroxyquinoline (1.4\%).

Although the mechanisms involved in the bio-synthesized of 

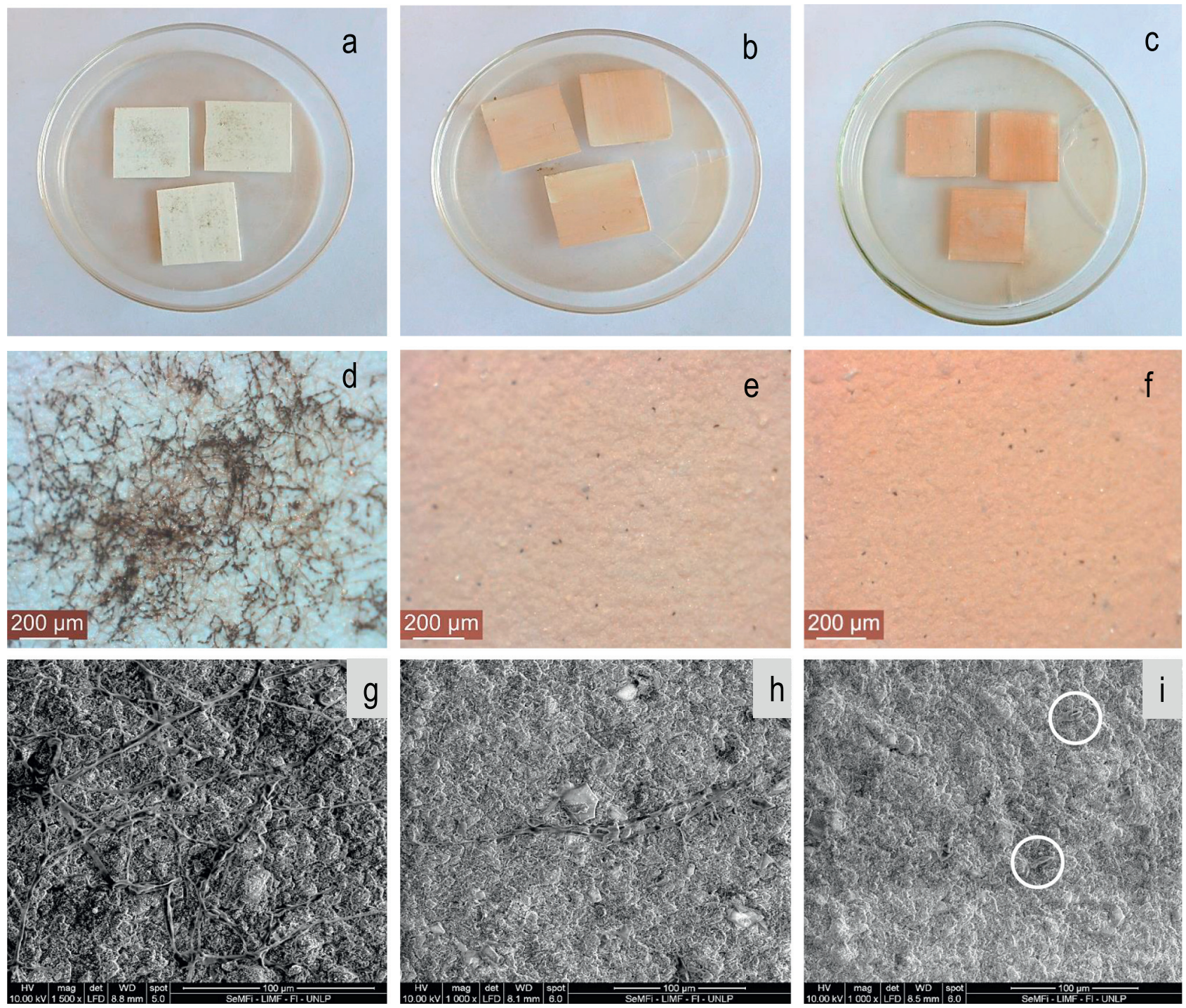

Fig. 4. Photographs records $(\mathrm{a}-\mathrm{c})$, stereoscopic microscope images $(\mathrm{d}-\mathrm{f})$ and SEM micrographs $(\mathrm{g}-\mathrm{i})$ from fungal resistance test against $A$. alternata: $\mathrm{P}$, control paint without biocide (a, d, g), P15 (b, e, h) and P25 (c, f, i) coatings samples with AgNPs. Spores highlighted by white circles.

nanoparticles is not entirely elucidated different studies point out that phytochemicals such as flavonoids or other phenolic based compounds are responsible for both the reduction and the stabilization of the nanoparticles (Bulut, 2009; Santhoshkumar et al., 2017; Makarov et al., 2014).

\subsection{Characterization of nanoparticles}

\subsubsection{UV-vis spectroscopy}

The products obtained with the $10^{-2} \mathrm{M}$ concentration of Ce, La and Zn salt solutions and plant extract were unstable and showed the formation of precipitates. Therefore, the synthesis process was repeated with a lower salt concentration $\left(10^{-3} \mathrm{M}\right)$ looking for stable suspensions.

UV-vis spectroscopy was carried out to confirm the presence of the NPs in the suspensions due to the appearance of characteristics absorption bands corresponding to surface plasmon resonance (SPR) Fig. 1a shows UV-vis spectra obtained $24 \mathrm{~h}$ of the synthesis. The spectrum of suspensions from $\mathrm{Ag}$ and $\mathrm{Cu}$ salts $\left(10^{-2} \mathrm{M}\right)$ exhibits absorption bands with higher and better defined maximum at 400 and $398 \mathrm{~nm}$, respectively. Suspensions from the synthesis with Ce, La and Zn salts $\left(10^{-3} \mathrm{M}\right)$ presented absorption peaks at 273, 275 and $265 \mathrm{~nm}$ with shoulders at 330, 350 and $355 \mathrm{~nm}$, respectively. In the case of Ce and La suspensions, peaks in 562 and $579 \mathrm{~nm}$ also have been observed.

The absorption peaks observed in the UV-vis spectrum would be indicating the presence of the NPs in the suspensions obtained. UV-vis spectra after 30 days showed that AgNPs and CuNPs suspensions were more stable maintaining the corresponding absorption bands. In the case of AgNPs suspension, an increase in absorption intensity and a redshift from 400 to $415 \mathrm{~nm}$ was observed (data not shown).

\subsubsection{Antimicrobial activity}

Firstly, the stable suspensions with peaks at the UV-vis spectrum were assessed against bacterial strains by the agar diffusion test. The suspensions from $\mathrm{Cu}, \mathrm{Ce}, \mathrm{La}$ and $\mathrm{Zn}$ salts and plant extract did not show inhibition zone around test disks against any of the strains used, therefore, resulted no active $(-)$. $\mathrm{Cu}, \mathrm{Ce}$, La and $\mathrm{Zn}$ salts solutions with the same concentrations used for the synthesis did not show antibacterial activity too. The AgNPs suspension with showed positive activity with inhibition zones of: $14.3 \pm 1.1$ and $14.6 \pm 0.7 \mathrm{~mm}$ against E. coli and $S$. aureus, respectively. Taking into account these results the antifungal activity assay was performed with the Ag NPs suspension, being the inhibition zone diameters obtained of: $6.15 \pm 0.3$ and $7.7 \pm 0.6 \mathrm{~mm}$ for $C$. globosum and A. alternata, respectively. These 

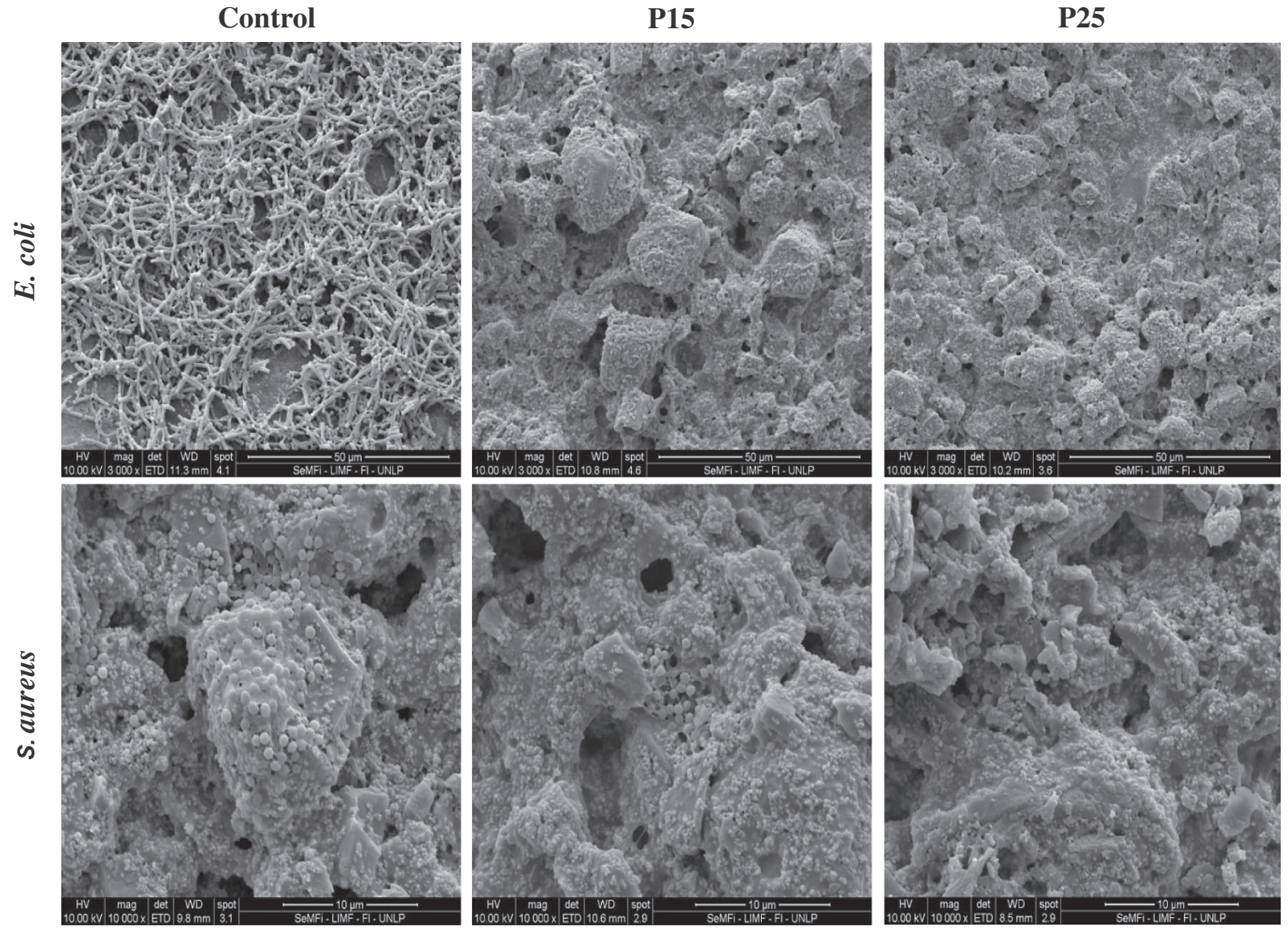

Fig. 5. SEM micrographs of paint films from antibacterial biofilm test with $E$. coli and $S$. aureus: P, control paint without biocide, P15 and P25 coatings samples with AgNPs.

results would be pointing out that the interaction of the NPs with the biogenic compounds is different in each case and this could influence their bioactivity. In Fig. 1b, plates from the diffusion test are showed. Data is expressed as mean \pm SD (standard deviation) of three experiments. The plant extract did not show antibacterial or antifungal activity at the same dilution used to the synthesis of nanoparticles.

\subsubsection{Electron microscopy and infrared spectroscopy}

After 30 days of the synthesis the more stable suspensions were those with $\mathrm{Ag}$ and $\mathrm{Cu}$. In view of these results, a deeper characterization was made. TEM micrographs confirmed the presence of nanoparticles in the synthesis products obtained from $\mathrm{Ag}$ and $\mathrm{Cu}$ salts and leaf extract of S. occidentalis. Fig. 2a and b shows the morphology of AgNPs and CuNPs. Organic based material from plant extracts can be seen around the particles. The histograms obtained by micrograph analysis in Fig. 2 show higher dispersion in CuNPs particle size compared to AgNPs which exhibited an average size of $15 \mathrm{~nm}$. These results confirmed the one obtained by UV-vis spectroscopy.

The FTIR spectra obtained from $S$. occidentalis extract and purified nanoparticles with $\mathrm{Ag}$ and $\mathrm{Cu}$ are showed in Fig. 3a. Plant extract band at $3265 \mathrm{~cm}^{-1}$ could be associated with $\mathrm{OH}$ groups in polyphenols compounds, both NPs presented this band but shifted to $3400 \mathrm{~cm}^{-1}$. Band at $2927 \mathrm{~cm}^{-1}$ would be associated with amino groups in proteins (Makarov et al., 2014). This is present in the case of CuNPs while with the AgNPs it was not observed. This fact could be attributed to a stronger association of CuNPs with amino groups. The peak at $1630 \mathrm{~cm}^{-1}$ may be attributed to carbonyl $-\mathrm{C}=\mathrm{O}$ stretching, present in peptides and flavonoids. The peak around 1397 and $1070 \mathrm{~cm}^{-1}$ could be attributed to a geminal methyl group and ether linkages, respectively. The FTIR spectra proved that biomolecules are strongly associated with the NPs and depending of the metal ions used to the synthesis functional groups could change. The SEM micrograph in Fig. 3b from purified AgNPs revealed a homogenous surface and the EDS profile from this in Fig. 3c, confirmed the presence of silver with a characteristic peak observed $\sim 3 \mathrm{keV}$ (Barberia-Roque et al., 2018; Dipankar and Murugan, 2012). In addition to this, EDS profile showed characteristic peaks from organic matter: $\mathrm{C}, \mathrm{O}, \mathrm{S}$ and P confirming the result of FTIR spectra (Makarov et al., 2014).

\subsection{Hygienic waterborne coatings}

\subsubsection{Fungal resistance assay}

The assessment of the fungal resistance of coatings presented some promising results. On the control paint (P), which did not contain AgNPs, C. globosum exhibited a growth rating as 3 according to the ASTM norm with higher fungal development and evident sporulation. The fungal growth decreased proportional to the increase in the concentration of AgNps in the coatings. A higher inhibitory activity was observed in samples P15 and P25 being rating as 0 (none growth) while for P10 the rating was 1 (trace of growth).

Fig. 4 shows images from fungal resistance test against $A$. alternata of the samples: P, P15 and P25 which yielded different results. P samples showed heavy growth $(\mathrm{R}=4)$ while the samples: P10, P15 and P25 resulted with ratings of 2, 1 and 0 , respectively. SEM microphotographs were determinant to find the differences between P15 and P25. The spores observed on P25 samples (Fig. 4) highlighted by white circles, were deposited as part of the inoculation to perform the assay and failed to germinate. However, in the case of the spores inoculated on P15 samples and observed in Fig. 4 manage to germinate. These differences could not be observed with a naked eye or with the 
stereoscopic microscope. In contrast, the fungal development that is observed on the blank paint samples was higher with an extended and intricate network of hyphae.

The bioassay performed showed that $A$. alternata resulted more resistant than C. globosum to grow on the hygienic coatings in such conditions. This could be attributed to the differentiated water requirements to colonize and grow on materials for each strain used. $C$. globosum has been reported to have higher water requirements with a water activity (aw) required ${ }^{>} 0.9$ while for A. alternata aw is $<0.9$ (Grant et al., 1989; Nielsen, 2002).

\subsubsection{Antibacterial biofilm assay}

SEM micrographs of coatings inoculated with bacteria are showed in Fig. 5. E. coli and $S$. aureus are widely studied for their high capacity for biofilm formation. This potentiality was tested against P15 and P25 samples (with AgNPs) and P (blank) without nanoparticles. The observation of $\mathrm{P}$ samples resulted in a constituted and distributed biofilm which can be seen in Fig. 5 for $E$. coli and $S$. aureus, respectively. However, inhibited bacterial growth were observed in the case of P15 and P25 samples, these results are showed in Fig. 5, respectively. In these micrographs surfaces of coatings are well appreciated and only some bacterial isolates can be observed on the surface, especially in the case of P25. This shows that $25 \mathrm{mg}$ of silver per $100 \mathrm{~g}$ proved to be an optimal concentration to prevent the biofilm formation on this paint. The results are consistent with each other and agree with those obtained in the test against fungi.

\section{Conclusion}

For the first time $S$. occidentalis leaf extract was employed for AgNPs synthesis, an antimicrobial additive, through a low cost and green process. This kind of products has several possible applications in pharmaceutical, food and coating industry.

The paint additives with the nanoparticles obtained in this work from $S$. occidentalis have the potential to prevent the formation of both fungal and bacterial biofilms with $25 \mathrm{mg}$ of silver per $100 \mathrm{~g}$ of paint which resulted in a very low concentration for a hygienic coating.

\section{Author contributions}

The manuscript was written through contributions of all authors. All authors have given approval to the final version of the manuscript.

\section{Funding sources}

The funds used to support the present research came from CONICET, CICPBA, ANCyT, and UNLP.

\section{Declaration of competing interest}

The authors declare that they have no conflict of interest.

\section{Acknowledgment}

Authors are thankful to CONICET, CICPBA, ANCyT, and UNLP. They also thank Dra. Cecilia Deyá for her support, Claudio Cerruti for the FTIR spectra and the technical support of the Ing. Pablo Bellotti.

\section{References}

Adan, Samson, 2011. Fundamentals of mold growth in indoor environments and strategies for healthy living. In: Fundamentals of Mold Growth in Indoor Environments and Strategies for Healthy Living, https://doi.org/10.3920/978-90-8686-722-6.

Barberia-Roque, L., Gámez-espinosa, E., Viera, M., Bellotti, N., 2018. Assessment of three plant extracts to obtain silver nanoparticles as alternative additives to control biodeterioration of coatings. Int. Biodeterior. Biodegrad. 0-1. https://doi.org/10.1016/j. ibiod.2018.06.011.
Barberia-Roque, L., Gámez-Espinosa, E., Viera, M., Bellotti, N., 2019. Assessment of three plant extracts to obtain silver nanoparticles as alternative additives to control biodeterioration of coatings. Int. Biodeterior. Biodegrad. 141. https://doi.org/10.1016/ j.ibiod.2018.06.011.

Bellotti, N., Salvatore, L., Deyá, C., Del Panno, M.T., del Amo, B., Romagnoli, R., 2013. The application of bioactive compounds from the food industry to control mold growth in indoor waterborne coatings. Colloids Surfaces B Biointerfaces 104. https:// doi.org/10.1016/j.colsurfb.2012.11.037.

Bellotti, N., Romagnoli, R., Quintero, C., Domínguez-Wong, C., Ruiz, F., Deyá, C., 2015. Nanoparticles as antifungal additives for indoor water borne paints. Prog. Org. Coatings 86. https://doi.org/10.1016/j.porgcoat.2015.03.006.

Bulut, E., 2009. Rapid, Facile Synthesis of Silver Nanostructure Using Hydrolyzable Tannin 5686-5690.

Chung, P.Y., Toh, Y.S., 2014. Anti-biofilm agents: recent breakthrough against multi-drug resistant Staphylococcus aureus. Pathog. Dis. 70, 231-239. https://doi.org/10.1111/ 2049-632X.12141.

Clegg, F., Breen, C., Muranyi, P., Schönweitz, C., 2019. Antimicrobial, starch based barrier coatings prepared using mixed silver/sodium exchanged bentonite. Appl. Clay Sci. 179, 105144. https://doi.org/10.1016/j.clay.2019.105144.

Deyá, C., Bellotti, N., 2017. Biosynthesized silver nanoparticles to control fungal infections in indoor environments. Adv. Nat. Sci. Nanosci. Nanotechnol. 8. https://doi. org/10.1088/2043-6254/aa6880.

Dipankar, C., Murugan, S., 2012. The green synthesis, characterization and evaluation of the biological activities of silver nanoparticles synthesized from Iresine herbstii leaf aqueous extracts. Colloids Surfaces B Biointerfaces 98, 112-119. https://doi.org/10. 1016/j.colsurfb.2012.04.006.

Dominguez-Wong, C., Loredo-Becerra, G.M., Quintero-González, C.C., Noriega-Treviño, M.E., Compeán-Jasso, M.E., Niño-Martínez, N., Dealba-Montero, I., Ruiz, F., 2014. Evaluation of the antibacterial activity of an indoor waterborne architectural coating containing $\mathrm{Ag} / \mathrm{TiO} 2$ under different relative humidity environments. Mater. Lett. 134, 103-106. https://doi.org/10.1016/j.matlet.2014.07.067.

Dubey, T., 2016. Indoor air pollution due to mycoflora causing acute lower respiratory infections. The Microbiology of Respiratory System Infections. Elsevier Inc. https:// doi.org/10.1016/b978-0-12-804543-5.00007-5.

Falkiewicz-Dulik, M., Janda, K., Wypych, G., 2015. Analytical methods in biodegradation, biodeterioration, and biostabilization. Handb. Mater. Biodegrad. Biodeterior. Biostablization 377-393. https://doi.org/10.1016/b978-1-895198-87-4.50011-6.

Fernández, M.A., Bellotti, N., 2017. Silica-based bioactive solids obtained from modified diatomaceous earth to be used as antimicrobial filler material. Mater. Lett. 194. https://doi.org/10.1016/j.matlet.2017.01.144.

Grant, C., Hunter, C.A., Flannigan, B., Bravery, A.F., 1989. The moisture requirements of moulds isolated from domestic dwellings. Int. Biodeterior. 25, 259-284. https://doi. org/10.1016/0265-3036(89)90002-X.

Haupert, F., Wetzel, B., 2005. Polymer Composites From Nano- to Macro-scale. Springer.

Hendessi, S., Sevinis, E.B., Unal, S., Cebeci, F.C., Menceloglu, Y.Z., Unal, H., 2016. Antibacterial sustained-release coatings from halloysite nanotubes/waterborne polyurethanes. Prog. Org. Coatings 101, 253-261. https://doi.org/10.1016/j. porgcoat.2016.09.005.

Jansz, J., 2016. Sick Building Syndrome, Third Edit. ed, International Encyclopedia of Public Health. Elsevier. https://doi.org/10.1016/B978-0-12-803678-5.00407-0.

Johns, K., 2003. Hygienic coatings: the next generation. Surf. Coatings Int. Part B Coatings Trans. 86, 101-110. https://doi.org/10.1007/BF02699620.

Knutsen, A.P., Bush, R.K., Demain, J.G., Denning, D.W., Dixit, A., Fairs, A., Greenberger, P.A., Kariuki, B., Kita, H., Kurup, V.P., Moss, R.B., Niven, R.M., Pashley, C.H., Slavin, R.G., Vijay, H.M., Wardlaw, A.J., 2012. Fungi and allergic lower respiratory tract diseases. J. Allergy Clin. Immunol. 129, 280-291. https://doi.org/10.1016/j.jaci. 2011.12.970.

Kumar, V., Yadav, S.K., 2009. Plant-mediated synthesis of silver and gold nanoparticles and their applications. J. Chem. Technol. Biotechnol. 84, 151-157. https://doi.org/ 10.1002/jctb.2023.

Kumar, S., Singh, M., Halder, D., Mitra, A., 2014. Mechanistic study of antibacterial activity of biologically synthesized silver nanocolloids. Colloids Surfaces A Physicochem. Eng. Asp. 449, 82-86. https://doi.org/10.1016/j.colsurfa.2014.02. 027.

Li, D.W., Yang, C.S., 2004. Fungal contamination as a major contributor to sick building syndrome. Adv. Appl. Microbiol. 55, 31-112. https://doi.org/10.1016/S00652164(04)55002-5.

Lok, C., Ho, C., Chen, R., He, Q., 2006. Proteomic analysis of the mode of antibacterial action of silver nanoparticles. Proteome Res. 916-924. https://doi.org/10.1021/ pr0504079.

V. V. Makarov et al., 2014. "Green" nanotechnologies: synthesis of metal nanoparticles using plants. Acta Naturae 6, 35-44. https://doi.org/10.1039/c1gc15386b

Mittal, A.K., Chisti, Y., Banerjee, U.C., 2013. Synthesis of metallic nanoparticles using plant extracts. Biotechnol. Adv. 31, 346-356. https://doi.org/10.1016/j.biotechadv. 2013.01.003.

Morones, J.R., Elechiguerra, J.L., Camacho, A., Holt, K., Kouri, J.B., Ramírez, J.T., Yacaman, M.J., 2005. The bactericidal effect of silver nanoparticles. Nanotechnology 16, 2346-2353. https://doi.org/10.1088/0957-4484/16/10/059.

Nguyen Tri, P., Nguyen, T.A., Nguyen, T.H., Carriere, P., 2019. Antibacterial behavior of hybrid nanoparticles. Noble Met. Oxide Hybrid Nanoparticles 141-155. https://doi. org/10.1016/b978-0-12-814134-2.00007-3.

Nguyen-Tri, P., Nguyen, V., Nguyen, T., 2019. Biological activity and nanostructuration of Fe3O4-Ag/high density polyethylene nanocomposites. J. Compos. Sci. 3, 34. https://doi.org/10.3390/jcs3020034.

Nielsen, K.F., 2002. Mould Growth on Building Materials. Danish Building and Urban Research. 
Odeja, O., Obi, G., Ogwuche, C.E., Elemike, E.E., Oderinlo, Y., 2015. Phytochemical screening, antioxidant and antimicrobial activities of Senna occidentalis (L.) leaves extract. Clin. Phytoscience 1 (6). https://doi.org/10.1186/s40816-015-0007-y.

Odunayo, R., Ayomadewa, A., Olatunya, M., 2014. Phytochemical screening and mineral composition of the bark of some medicinal trees in Ondo State. Nigeria 2, 44-49.

Peraica, M., Radic, B., Lucic, A., Pavlovic, M., 1999. Toxic effects of mycotoxins in humans. Bull. World Health Organ. 77, 754-766.

Rajeshkumar, S., Bharath, L.V., 2017. Mechanism of plant-mediated synthesis of silver nanoparticles - a review on biomolecules involved, characterisation and antibacterial activity. Chem. Biol. Interact. 273, 219-227. https://doi.org/10.1016/j.cbi.2017.06. 019.

Roselli, S., Bellotti, N., Deyá, C., Revuelta, M., Del Amo, B., Romagnoli, R., 2014. Lanthanum-exchanged zeolite and clay as anticorrosive pigments for galvanized steel. J. Rare Earths 32. https://doi.org/10.1016/S1002-0721(14)60078-8.
Santhoshkumar, J., Rajeshkumar, S., Venkat Kumar, S., 2017. Phyto-assisted synthesis, characterization and applications of gold nanoparticles - a review. Biochem. Biophys. Reports 11, 46-57. https://doi.org/10.1016/j.bbrep.2017.06.004.

Shrivastava, S., Bera, T., Roy, A., Singh, G., Ramachandrarao, P., Dash, D., 2007. Characterization of enhanced antibacterial effects of novel silver nanoparticles. Nanotechnology 18. https://doi.org/10.1088/0957-4484/18/22/225103.

Singh, P., Kim, Y.J., Zhang, D., Yang, D.C., 2016. Biological synthesis of nanoparticles from plants and microorganisms. Trends Biotechnol. 34, 588-599. https://doi.org/ 10.1016/j.tibtech.2016.02.006.

Weber, D.J., Anderson, D., Rutala, W.A., 2013. The role of the surface environment in healthcare-associated infections. Curr. Opin. Infect. Dis. 26, 338-344. https://doi. org/10.1097/QCO.0b013e3283630f04.

WHO, 2009. WHO Guidelines for Indoor Air Quality: Dampness and Mould. 